\title{
Clorofilômetro no ajuste da adubação nitrogenada em cobertura para o milho de alta produtividade
}

\author{
Nitrogen top dressing for high yield corn based on the chlorophyll meter readings \\ Sandro Manuel Carmelino Hurtado ${ }^{\mathrm{I} *}$ Álvaro Vilela de Resende ${ }^{\mathrm{II}}$ Carlos Alberto Silva ${ }^{\mathrm{I}}$ \\ Edemar Joaquim Corazza ${ }^{\text {III }}$ Luciano Shozo Shiratsuchi ${ }^{\text {IV }}$
}

\section{RESUMO}

A avaliação do conteúdo relativo de clorofila nas folhas fornece uma medida indireta do estado nutricional das plantas e pode ajudar os agricultores no ajuste da quantidade de nitrogênio (N) a ser aplicada em cobertura no milho. Objetivou-se neste trabalho validar o uso do clorofilômetro na detecção e correção da deficiência de $N$ ao longo do ciclo vegetativo da cultura. O experimento foi conduzido em parcelas estabelecidas numa lavoura comercial, sendo o estado nutricional das plantas monitorado semanalmente com o uso do clorofilômetro. Os tratamentos incluíram uma testemunha $\left(0 \mathrm{~kg} \mathrm{ha}^{-1}\right)$ e quatro doses de $\mathrm{N}$ em cobertura (45, 90, $135 \mathrm{e}$ $\left.180 \mathrm{~kg} \mathrm{ha}^{-1}\right)$, considerando-se o índice de suficiência de nitrogênio (ISN) de 0,95, o qual foi monitorado com o clorofilômetro, a partir de um tratamento referência $(500 \mathrm{~kg}$ $h a^{-1}$ de N). O uso do clorofilômetro indicou a aplicação de $N$ até $180 \mathrm{~kg} \mathrm{ha}^{-1}$, extrapolando as quantidades requeridas para máxima eficiência técnica (144kg ha-1) ou econômica $(105 \mathrm{~kg}$ $\left.h \mathrm{~h}^{-1}\right)$. O estabelecimento de parcelas referência possibilita usar o clorofilômetro como indicador da necessidade de aplicação de $\mathrm{N}$ em cobertura durante o ciclo do milho, não obstante, o uso do valor de ISN 0,95 durante todo o ciclo da cultura pode não ser a estratégia mais apropriada.

Palavras-chave: nitrogênio, SPAD, índice de suficiência de nitrogênio, agricultura de precisão.

\section{ABSTRACT}

The evaluation of the chlorophyll relative content in the leaves provides an indirect measure of the plant's nutritional status and can help farmers to adjust the quantity of nitrogen $(N)$ to be applied as top dressing fertilization for corn. The aim of this work was to validate the use of chlorophyll meter for detection and correction of $N$ deficiency during the crop vegetative growth. The experiment was carried out in plots under commercial crop conditions and the corn nutritional status was monitored weekly with the chlorophyll meter. Six treatments of top dressing $N$ included a check $\left(0 \mathrm{~kg} \mathrm{ha}^{-1}\right)$ and four doses $\left(45,90,135\right.$ and $\left.180 \mathrm{~kg} \mathrm{ha}^{-1}\right)$, considering the nitrogen sufficiency index (NSI) of 0.95 monitored with the chlorophyll meter based on a reference treatment $\left(500 \mathrm{~kg} \mathrm{ha}^{-1}\right)$. The chlorophyll meter indicated top dress $N$ application for corn up to $180 \mathrm{~kg} \mathrm{ha}^{-1}$, exceeding the quantities required to maximize the technical (144kg ha-1) or economic $\left(105 \mathrm{~kg} \mathrm{ha}^{-1}\right)$ efficiency. The establishment of reference plots makes the chlorophyll meter an useful indicator of the need of $N$ top dressing during the corn growth, however, the use of the 0,95 NSI value throughout the crop cycle may not be the most appropriate strategy.

Key words: nitrogen, SPAD, nitrogen sufficiency indices, precision agriculture.

\section{INTRODUÇÃO}

Além de ser afetado por condicionantes ligados ao clima, ao relevo e ao manejo, o nitrogênio (N) participa em diversas reações e possui diferentes formas no solo, apresentando dinâmica complexa, o que dificulta a avaliação da sua disponibilidade e recomendações precisas de fornecimento às culturas.

IDepartamento de Ciência do Solo, Universidade Federal de Lavras (UFLA), 37200-000, Lavras, MG, Brasil. E-mail: sandroelbat@gmail.com. *Autor para correspondência.

"Embrapa Milho e Sorgo, Sete Lagoas, MG, Brasil.

"Embrapa Informação Tecnológica, Brasília, DF, Brasil.

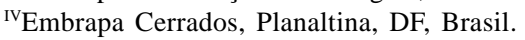


Desse modo, as recomendações de adubação nitrogenada são norteadas por estimativas da capacidade de suprimento de $\mathrm{N}$ pelo solo, pela expectativa de produtividade, teor de $\mathrm{N}$ foliar e teor de matéria orgânica do solo (RAIJ et al., 1996; AMADO et al., 2002), além de se mostrarem dependentes dos esquemas de sucessão/rotação de culturas (AMADO et al., 2002) e da eficiência de uso da fonte aplicada.

Comumente, a quantidade de $\mathrm{N}$ na adubação do milho no Cerrado é definida previamente à semeadura, sem monitoramento posterior à emergência das plantas. Uma pequena porção (20 a 30kg ha-1) é fornecida na semeadura e o restante em uma ou mais aplicações em cobertura durante o desenvolvimento da lavoura (SOUSA \& LOBATO, 2004). A definição precisa da dose é uma meta difícil de ser alcançada e, a cada dia, torna-se mais importante, pelo fato de o $\mathrm{N}$ ser requerido em grandes quantidades pela cultura, devido ao seu custo elevado e em função das restrições impostas pela legislação (especificamente para os Estados Unidos de Norte América e Europa) quanto à contaminação do ambiente com $\mathrm{N}$, aplicado em excesso nas lavouras. Por outro lado, o emprego de subdoses de $\mathrm{N}$ restringe fortemente a produtividade do milho (HAWKINS et al., 2007).

Em princípio, maior eficiência pode ser alcançada melhorando-se a sincronização entre as aplicações de adubo nitrogenado e os estádios de maior demanda pelo milho, sobretudo na fase inicial (quatro folhas), época em que é definido o potencial produtivo da cultura (RITCHIE et al., 2003). Diversos indicadores da disponibilidade de $\mathrm{N}$ no solo e na planta têm sido propostos, entretanto, os referentes à planta merecem destaque pela sua capacidade de integrar fatores condicionantes relacionados ao solo e ao ambiente (CANTARELLA, 2007).

Em condições brasileiras, o monitoramento da disponibilidade de $\mathrm{N}$ para o milho, utilizando a própria planta, tem envolvido principalmente leituras do teor relativo de clorofila nas folhas (ARGENTA et al., 2003, 2004; GODOY et al., 2007). Contudo, a indicação de valores de leituras do clorofilômetro como referência para se inferir sobre a disponibilidade de $\mathrm{N}$ nos diversos estádios da cultura (ARGENTA et al., 2003, 2004) pode representar riscos em virtude de variações nas leituras, que são condicionadas por diferenças de híbridos, épocas, locais e anos agrícolas (WASKOM et al., 1996; HAWKINS et al., 2007; ZHANG et al., 2008). Um aspecto preponderante é que, em lavouras, ao contrário de experimentos controlados, o rendimento do milho se mostra dependente de outros fatores além dos ligados ao estado nutricional em N (ZHANG et al., 2008).

O estabelecimento de parcelas de referência nas áreas de cultivo, com suficiente suprimento de N, é uma maneira de contornar a ausência de significado direto das leituras do clorofilômetro (BLACKMER \& SCHEPERS, 1994), além de permitir obtenção de informações particularizadas para as condições locais. Assim, é possível trabalhar com índices de suficiência de nitrogênio (ISN), em que leituras inferiores a, por exemplo, 95\% do valor obtido nas parcelas referência indicariam uma situação de deficiência nutricional (BLACKMER \& SCHEPERS, 1994; VARVEL et al., 1997) e a necessidade de aplicação de $\mathrm{N}$ em cobertura. Todavia, respostas controversas frente ao uso do clorofilômetro têm sido relatadas (VARVEL et al., 1997; GODOY et al., 2003; RAMBO et al., 2008).

Este trabalho teve por objetivo validar o uso do clorofilômetro na detecção e correção de deficiências de $\mathrm{N}$ durante o ciclo do milho, visando a compatibilizar a quantidade do nutriente na adubação com a demanda e resposta produtiva da cultura no Cerrado.

\section{MATERIAL E MÉTODOS}

O estudo foi conduzido em lavoura de sequeiro, na Fazenda Alto Alegre (Planaltina de Goiás, GO), com sucessão milho-soja, sem preparo do solo há cinco anos. O talhão apresenta ocorrência expressiva de Brachiaria decumbens e outras gramíneas, as quais servem ao pastejo nos períodos de pousio. No início da safra de milho 2006/07, o Latossolo VermelhoAmarelo da área (camada de 0-0,2m) apresentou, respectivamente, os seguintes valores para os teores de argila ( $\left.\mathrm{g} \mathrm{kg}^{-1}\right)$; matéria orgânica ( $\left.\mathrm{g} \mathrm{dm}^{-3}\right)$; $\mathrm{pH}_{\text {água }}$; $\mathrm{P}_{\text {Mehlich } 1}\left(\mathrm{mg} \mathrm{dm}{ }^{-3}\right) ; \mathrm{K}^{+}, \mathrm{Ca}^{2+}, \mathrm{Mg}^{2+}, \mathrm{Al}^{3+}$, CTC a pH 7 $\left(\mathrm{cmol}_{\mathrm{c}} \mathrm{dm}^{-3}\right)$; e V(\%): 540; 9; 5,7; 9; 0,5; 1,5; 0,5; 0,1; 6,9 e 37.

Antes da semeadura do milho, foi aplicada 1t ha-1 de calcário dolomítico em superfície. Em sequência, foi semeado o híbrido simples Pioneer 30F90, em 06/11/2006, o qual foi adubado com $350 \mathrm{~kg} \mathrm{ha}^{-1} \mathrm{de}$ NPK 06-23-18 (contendo 2; 4; 0,13; 0,09; 0,13 e 0,4\% de $\mathrm{Ca}, \mathrm{S}, \mathrm{B}, \mathrm{Cu}, \mathrm{Mn}$ e Zn, respectivamente). A semeadura e os tratos culturais foram realizados conforme procedimentos operacionais da fazenda. O regime hídrico foi favorável durante o período experimental, com chuvas abundantes e bem distribuídas.

Os tratamentos com doses de $\mathrm{N}$ em cobertura foram comparados em parcelas com 5 linhas, cada uma com $6 \mathrm{~m}$ de comprimento, espaçadas em $0,7 \mathrm{~m}$, com cinco plantas por metro. As avaliações foram feitas nas três linhas centrais, com bordaduras de $1 \mathrm{~m}$ nas extremidades. Utilizou-se o delineamento experimental em blocos casualizados com três repetições. Das seis doses de $\mathrm{N}$ avaliadas $\left(0,45,90,135,180\right.$ e $\left.500 \mathrm{~kg} \mathrm{ha}^{-1}\right)$, 
as quatro intermediárias foram utilizadas associadas ao Índice de Suficiência de Nitrogênio (ISN), que foi monitorado com o clorofilômetro, enquanto as doses extremas constituíram um tratamento testemunha $(0 \mathrm{~N})$ e o tratamento referência sem limitação no suprimento de $\mathrm{N}(500 \mathrm{~N})$. O tratamento referência (ou parcelas de referência) foi adotado conforme sugerido por BLACKMER \& SCHEPERS (1994) a fim de permitir o monitoramento do estado nutricional do milho por meio do ISN.

O tratamento $500 \mathrm{~N}$ foi parcelado em aplicações semanais ao longo dos estádios de desenvolvimento do milho (RITCHIE et al., 2003) a partir do estádio $\mathrm{V}_{2}$, sendo fornecidos $50 \mathrm{~kg} \mathrm{ha}^{-1}$ na primeira aplicação e $75 \mathrm{~kg} \mathrm{ha}^{-1}$ nas seguintes aplicações, correspondendo aos estádios $\mathrm{V}_{3-4} ; \mathrm{V}_{4-5} ; \mathrm{V}_{5-6} ; \mathrm{V}_{7-8} ; \mathrm{V}_{9-10}$ e $V_{11-12}$, até completar a dose total. O ISN foi calculado semanalmente com uso do clorofilômetro Minolta SPAD $502^{\circledR}$, a partir da relação entre as leituras do teor relativo de clorofila das parcelas destinadas ao manejo da adubação de cobertura e as leituras obtidas no tratamento referência $(500 \mathrm{~N})$. As leituras foram iniciadas no estádio de duas folhas $\left(\mathrm{V}_{2}\right)$ e finalizadas três semanas após o florescimento feminino $\left(\mathrm{R}_{3}\right)$. Em cada época, foram obtidas dez leituras por parcela, sempre utilizando cinco plantas marcadas com fitas coloridas. As leituras foram realizadas de cada lado do limbo foliar, no terço médio, desconsiderando-se a nervura central e as margens (ARGENTA et al., 2001), na última folha totalmente expandida (até o florescimento) ou na folha indicadora abaixo e oposta à espiga (após o florescimento).

As coberturas foram realizadas 24 horas depois de obtidos os ISN. O adubo utilizado, Super N (33\% N e 11\% S), consistiu de mistura comercial de grânulos (1:1) de sulfato de amônio e uréia revestida com inibidor de urease (NBPT). O adubo foi aplicado manualmente na superfície, a $20 \mathrm{~cm}$ da linha de plantas. Foi alocado um número suficiente de parcelas experimentais que, progressivamente, receberiam $45 \mathrm{~kg}$ $\mathrm{ha}^{-1}$ de $\mathrm{N}$, quando o monitoramento nutricional indicasse ISN<0,95 (BLACKMER \& SCHEPERS, 1995; VARVEL et al., 1997; GODOY et al., 2003). A partir da primeira cobertura, a cada vez que houve indicação de nova aplicação de $\mathrm{N}(\mathrm{ISN}<0,95)$, uma das parcelas já adubadas foi deixada como controle. Esse procedimento foi repetido até não ser mais detectada necessidade de $\mathrm{N}$, compondo, assim, as quatro doses intermediárias (45N, 90N, 135N e 180N).

Na colheita, foi quantificada a produção de grãos (13\% de umidade) na área útil das parcelas. Os dados foram submetidos à análise de variância, determinando-se modelos de regressão para as respostas às doses de N. Para cálculo da receita líquida, foram consideradas as cotações do milho-grão ( $\mathrm{R}$ \$24,00 sc60 $\mathrm{kg}^{-1}$ ) e do adubo nitrogenado ( $\left.\mathrm{R} \$ 933,00 \mathrm{t}^{-1}\right)$ em maio de 2007. A componente do custo referente às operações de aplicação do $\mathrm{N}$ em cobertura não foi considerada no cálculo. A equivalência dos valores, em dólar, pode ser obtida com base na cotação de R\$ 1,77 para o dólar americano (US\$). A estimativa da dose de $\mathrm{N}$ que maximizaria o retorno econômico foi determinada igualando-se a derivada da equação de resposta em produtividade à razão entre o custo do nitrogênio e o valor do produto colhido (RAIJ, 1991).

\section{RESULTADOS E DISCUSSÃO}

O padrão das curvas de leituras do clorofilômetro ao longo do ciclo do milho foi similar para as diferentes doses de $\mathrm{N}$, apresentando, contudo, diferenças na magnitude dos valores conforme o fornecimento do nutriente (Figura 1). No decorrer dos estádios vegetativos, verificaram-se leituras crescentes, as quais tenderam a estabilizar-se a partir do estádio de pré-florescimento $\left(\mathrm{V}_{14}-\mathrm{V}_{16}\right)$, corroborando os dados obtidos por GODOY et al. (2003) e ARGENTA et al. (2004). Tal comportamento pode ser explicado em função de os máximos teores de clorofila em folha serem atingidos pela cultura do milho nesse estádio de desenvolvimento (COSTA et al., 2001).

A dose $0 \mathrm{~N}$ e o tratamento referência (500N) proporcionaram valores contrastantes de leitura SPAD (Figura 1), permitindo detectar precocemente, com base no ISN de 0,95, a necessidade de cobertura no estádio $\mathrm{V}_{4}-\mathrm{V}_{5}$, aos 21 dias após a germinação (Figura 2). Tal fato é relevante, pois, além da maior facilidade operacional para aplicações mecanizadas, a correção de carências de $\mathrm{N}$ em plantas jovens assegura a obtenção de maior produtividade, em função do potencial produtivo do milho ser definido entre os estádios $\mathrm{V}_{4} \mathrm{e} \mathrm{V}_{6}$. A necessidade de cobertura, com base em ISN de 0,95, havia sido relatada a partir dos estádios $\mathrm{V}_{7}$ (GODOY et al., 2003), $\mathrm{V}_{8}$ (VARVEL et al., 1997) e $\mathrm{V}_{10}$ (WASKOM et al., 1996), épocas tardias e situações em que operações de aplicação de N com trator são menos viáveis.

Em condições intermediárias de suprimento de N (45, 90, 135 e 180 $\left.\mathrm{kg} \mathrm{ha}^{-1}\right)$, as diferenças de leitura SPAD foram menos perceptíveis (Figura 1). Esse aspecto comprova a utilidade das parcelas referência, com grande aporte de $\mathrm{N}$, para que se possa utilizar o clorofilômetro como indicador da necessidade de realização ou não da cobertura (BLACKMER \& SCHEPERS, 1995). Além disso, também se pode observar que, nessas condições, valores similares de 


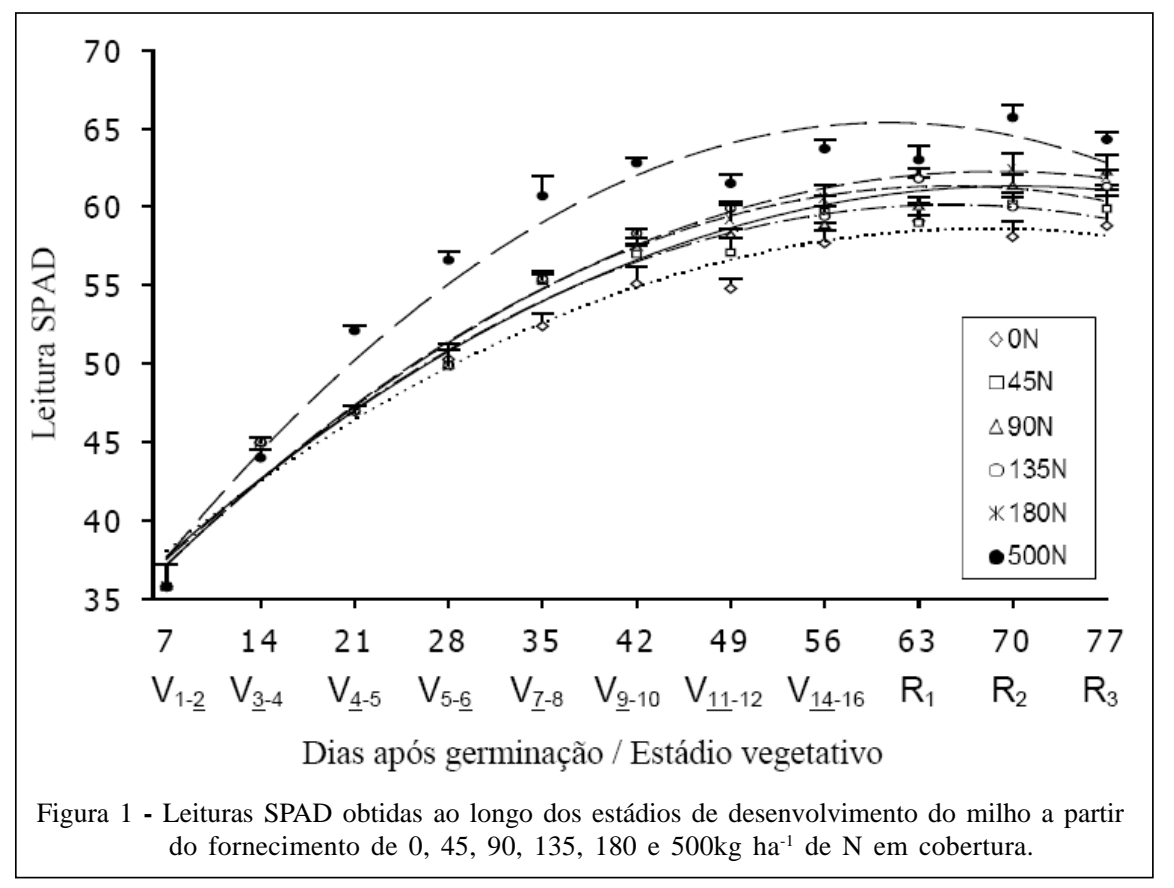

leitura SPAD podem ser obtidos para condições bastante discrepantes de suprimento de $\mathrm{N}$, denotando ser arriscada a indicação de valores de leituras do clorofilômetro como referência (ARGENTA et al., 2003; 2004) para se inferir a disponibilidade de $N$ para o milho.

Pelo critério do índice de suficiência de nitrogênio (ISN) de 0,95, foram necessárias quatro aplicações consecutivas, a cada sete dias, de $45 \mathrm{~kg} \mathrm{ha}^{-1}$ de $\mathrm{N}$ ao longo da fase de desenvolvimento vegetativo do milho (Figura 2). Portanto, somente quando as aplicações em cobertura totalizaram $180 \mathrm{~kg} \mathrm{ha}^{-1}$ de $\mathrm{N}$ as leituras SPAD aproximaram-se das obtidas nas parcelas referência (500N), mantendo, daí para frente, o ISN igual ou superior a 0,95 .

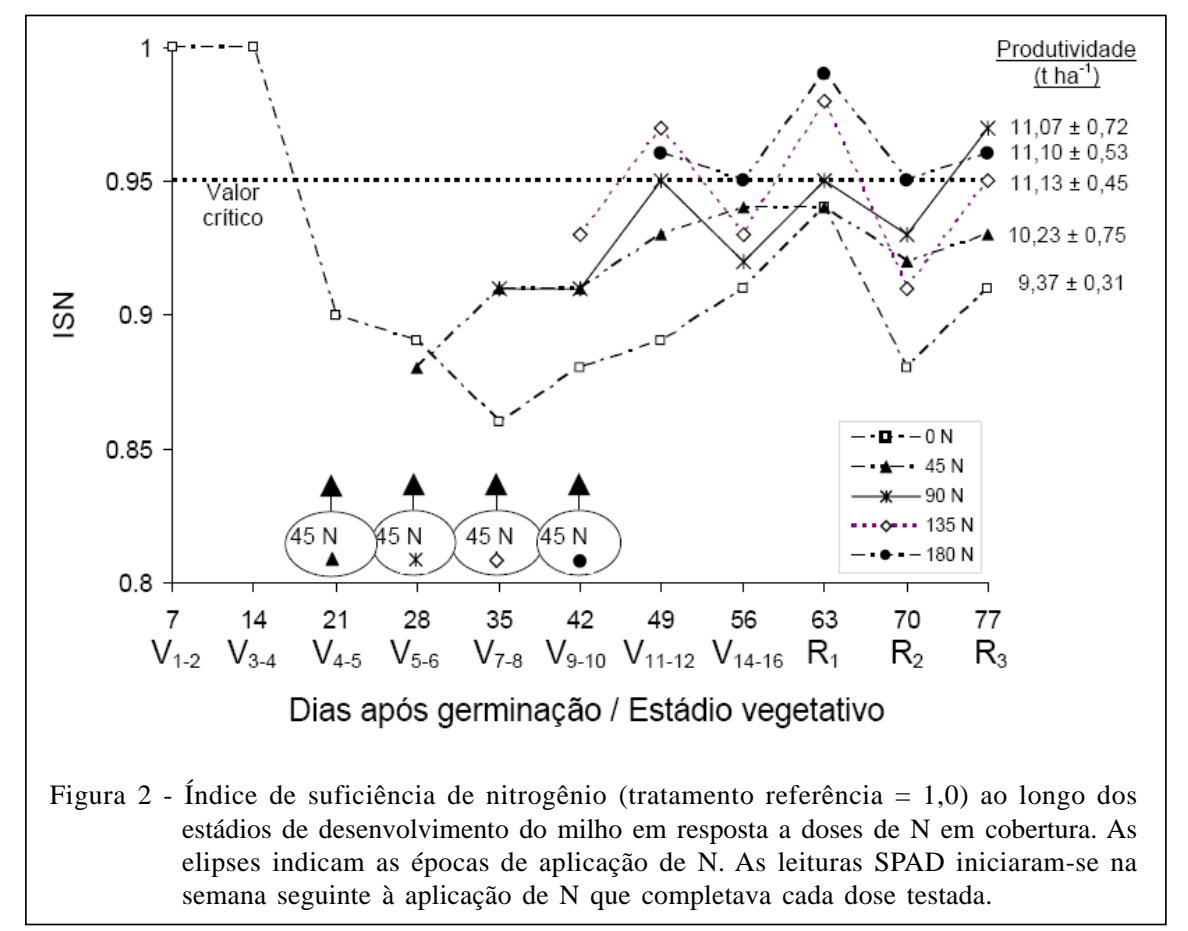

Ciência Rural, v.41, n.6, jun, 2011. 
No entanto, as respostas em produtividade e rentabilidade não foram proporcionais à quantidade de $\mathrm{N}$ em cobertura (Figura 3). De acordo com o modelo ajustado, a produtividade máxima estimada foi de 11,2t ha ${ }^{-1}$, obtida a partir da aplicação de $144 \mathrm{~kg} \mathrm{ha}^{-1}$ de N em cobertura. Para uma produtividade de $10 \mathrm{t} \mathrm{ha}^{-1}$, a dose cairia para $28 \mathrm{~kg} \mathrm{ha}^{-1}$, o que corrobora os dados de VARVEL et al. (1997) em área com sucessão soja-milho, onde a produtividade foi pouco influenciada além da dose de $50 \mathrm{~kg} \mathrm{ha}^{-1}$ de $\mathrm{N}$. A estimativa de dose para máxima receita líquida, considerando o custo do fertilizante nitrogenado e o valor do produto colhido, foi de $105 \mathrm{~kg} \mathrm{ha}^{-1}$ de $\mathrm{N}$. Assim, pode-se considerar que as leituras do clorofilômetro, quando considerado o valor de ISN 0,95 durante todo o ciclo, superestimaram a dose de $\mathrm{N}$ a ser aplicada em cobertura. Esta constatação põe em xeque a ideia de que o clorofilômetro pode ser usado com grande precisão para indicar a necessidade de adubação de cobertura em lavouras de milho.

Os coeficientes de correlação de Pearson obtidos entre os dados de leitura do clorofilômetro, teor foliar de $\mathrm{N}$ e produtividade de grãos reforçam as evidências de que nem sempre o equipamento permite predizer, com alto grau de confiabilidade, o estado nutricional vinculado ao potencial produtivo do milho em condições de campo. Para o intervalo de doses de 0 a $180 \mathrm{~kg} \mathrm{ha}^{-1}$ de $\mathrm{N}$, a alta e significativa correlação observada entre leitura do clorofilômetro e teor foliar de $\mathrm{N}$ no florescimento $\left(\mathrm{r}=0,80^{* *}\right)$ desaparece ao se relacionar leitura do clorofilômetro e produtividade $\left(\mathrm{r}=0,45^{\mathrm{ns}}\right)$ ou produtividade e $\mathrm{N}$ foliar $\left(\mathrm{r}=0,22^{\mathrm{ns}}\right)$.

Sobretudo, se considerada a necessidade de $\mathrm{N}$ associada ao maior retorno econômico (105kg ha-1), depreende-se que o clorofilômetro não permitiu o ajuste fino da dosagem, levando a uma superestimativa da quantidade a ser aplicada. Desse modo, os resultados ora obtidos levam a crer que o clorofilômetro se presta bem para discriminar condições contrastantes de suprimento de $\mathrm{N}$, mas, a partir de certo nível de disponibilidade do nutriente no sistema solo-planta, o equipamento não confere a sensibilidade necessária para se decidir precisamente sobre a viabilidade de fornecer pequenas doses adicionais, de $30 \mathrm{a} 40 \mathrm{~kg} \mathrm{ha}^{-1}$.

É importante ponderar que as razões para essa dissonância entre as medidas dos teores relativos de clorofila e as respostas do milho em produtividade não ficaram claras. Uma possibilidade é que o limite de ISN utilizado $(0,95)$ não seria o mais adequado ao longo de todo o ciclo da cultura. A necessidade de melhor ajuste do limite de ISN em função do estádio de desenvolvimento tem sido sugerida (PIEKIELEK et al., 1995; GODOY et al., 2003). De acordo com VARVEL et al. (1997), índices menores do que 0,90 a partir do estádio $\mathrm{V}_{8}$ podem comprometer definitivamente a produtividade. Assim, um limite de 0,90 poderia ser considerado a partir do estádio $\mathrm{V}_{8}$. Segundo esse critério, os $90 \mathrm{~kg} \mathrm{ha}^{-1}$ de $\mathrm{N}$ que foram aplicados com base no clorofilômetro até o estádio $\mathrm{V}_{5-6}$ (Figura 2) teriam constituído a dosagem máxima requerida no

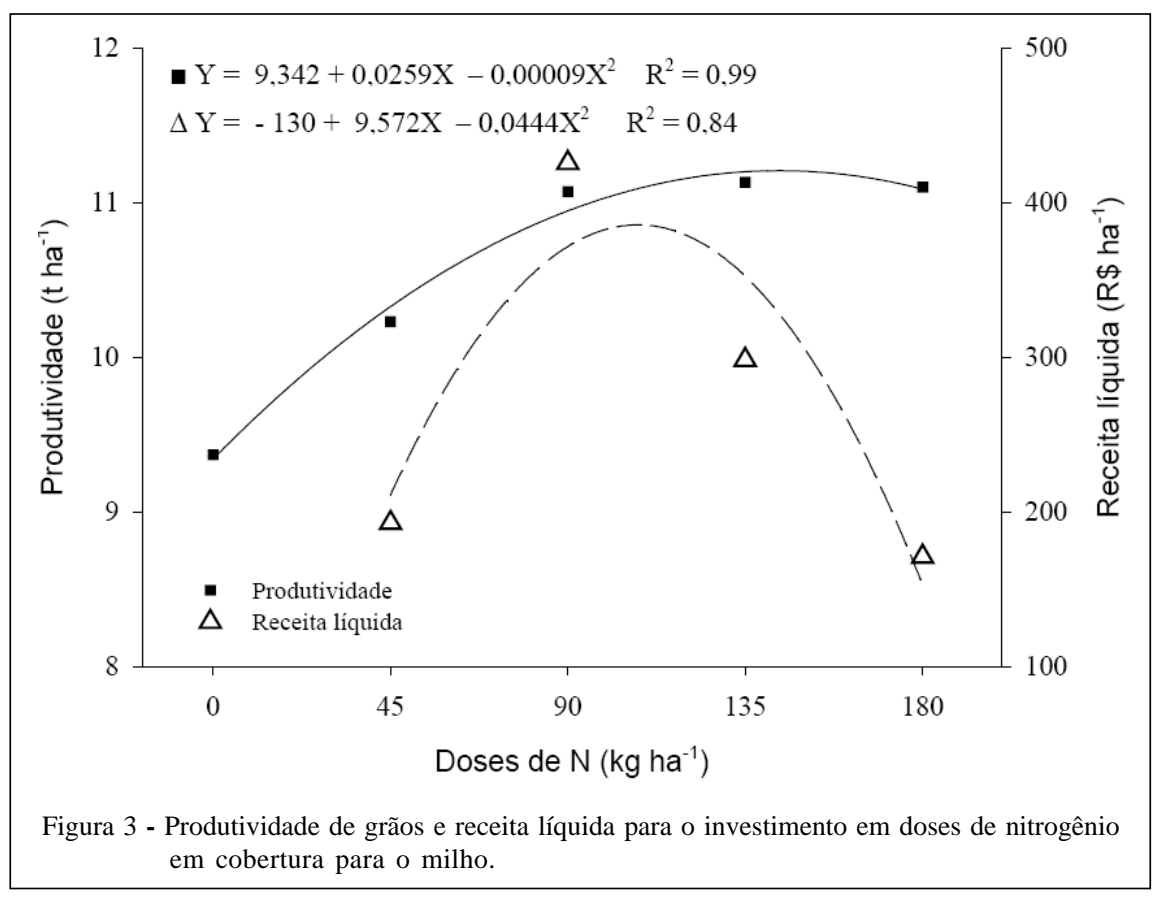

Ciência Rural, v.41, n.6, jun, 2011. 
experimento, aproximando-se da dose estimada para maior eficiência econômica (Figura 3).

As informações aqui apresentadas reafirmam a necessidade de se aferir e calibrar, localmente, o manejo do $\mathrm{N}$ baseado no uso do clorofilômetro, levando-se em conta as variantes peculiares ao sistema de produção adotado, mormente no caso de lavouras de milho de alta produtividade, em que os impactos na produtividade decorrentes de alterações do manejo da adubação costumam ser discretos.

\section{CONCLUSÃO}

O monitoramento das plantas com uso do clorofilômetro, baseado no índice de suficiência de nitrogênio 0,95 , indicou a necessidade de fornecimento de $\mathrm{N}$ até $180 \mathrm{~kg} \mathrm{ha}^{-1}$ em cobertura, extrapolando as quantidades requeridas para máxima eficiência técnica (144kg ha ${ }^{-1}$ ) ou econômica (105kg ha-1).

O estabelecimento de parcelas referência possibilita, por meio do cálculo do ISN, usar o clorofilômetro como indicador da necessidade de aplicação de $\mathrm{N}$ em cobertura durante o ciclo do milho. Não obstante, o uso do valor de ISN 0,95 durante todo o ciclo da cultura pode não ser a estratégia mais apropriada.

\section{REFERÊNCIAS}

AMADO, T.J.C. et al. Recomendação de adubação nitrogenada para o milho no RS e SC adaptada ao uso de culturas de cobertura do solo sob sistema plantio direto. Revista Brasileira de Ciência do Solo, v.26, p.241-248, 2002. Disponível em: <http://sbcs.solos.ufv.br/solos/revistas/v26n1a25.pdf>. Acesso em: 07 abr. 2011.

ARGENTA, G. et al. Relação da leitura do clorofilômetro com os teores de clorofila extraível e de nitrogênio na folha de milho. Revista Brasileira de Fisiologia Vegetal, v.13, p.158-167, 2001. Disponível em: <http:/ /www.scielo.br/scielo.php?script=sci_arttext\&pid=S010331312001000200005\&lng=pt\&nrm=iso>. Acesso em: 6 abr. 2011. doi: 10.1590/S0103-31312001000200005.

ARGENTA, G. et al. Adubação nitrogenada em milho pelo monitoramento do nível de nitrogênio na planta por meio do clorofilômetro. Revista Brasileira de Ciência do Solo, v.27, p.109-119, 2003. Disponível em: <http://sbcs.solos.ufv.br/solos/ revistas/v27n1a12.pdf $>$. Acesso em: 07 abr. 2011.

ARGENTA, G. et al. Leaf relative chlorophyll content as an indicator parameter to predict nitrogen fertilization in maize. Ciência Rural, v.34, n.5, p.1379-1387, 2004. Disponível em: <http:// www.scielo.br/scielo.php?script=sci_arttext\&pid=S010384782004000500009\&lng=pt\&nrm=iso>. Acesso em: 6 abr. 2011. doi: 10.1590/S0103-84782004000500009.

BLACKMER, M.; SCHEPERS, J.S. Techniques for monitoring crop nitrogen status in corn. Communications in Soil
Science and Plant Analysis, v.25, p.1791-1800, 1994. Disponível em: <http://www.informaworld.com/smpp/ content $\sim \mathrm{db}=\mathrm{all} \sim$ content $=\mathrm{a} 905369335 \sim \mathrm{frm}=\mathrm{abslink}>$. Acesso em: 6 abr. 2011. doi: 10.1080/00103629409369153.

BLACKMER, T.M.; SCHEPERS, J.S. Use of chlorophyll meter to monitor nitrogen status and schedule fertigation for corn. Journal of Production Agriculture, v.8, n.1, p.56-60, 1995. Disponível em: <http://ddr.nal.usda.gov/bitstream/10113/16751/ 1/IND20447709.pdf>. Acesso em: 07 abr. 2011.

CANTARELLA, H. Nitrogênio. In: NOVAIS, R.F. et al. (Org.). Fertilidade do solo. Viçosa, MG: SBCS, 2007. p.375-470.

COSTA, C. et al. Inter-relationships of applied nitrogen, SPAD, and yield of leafy and non-leafy maize genotypes. Journal of Plant Nutrition, v.24, n.8, p.1173-1194, 2001. Disponível e m : < h t t p / / w w w. in form a world. com/ s m p p / content $\sim \mathrm{db}=$ all $\sim$ content $=\mathrm{a} 713647511 \sim$ frm $=$ abslink $>$. Acesso em: 6 abr. 2011. doi: 10.1081/PLN-100106974.

GODOY, L.J.G. de et al. Adubação nitrogenada na cultura do milho baseada na medida do clorofilômetro e no índice de suficiência em nitrogênio (ISN). Acta Scientiarum, Agronomy, v.25, n.2, p.373-380, 2003. Disponível em: <http:/ /periodicos.uem.br/ojs/index.php/ActaSciAgron/article/view/ 1985/1602>. Acesso em: 6 abr. 2011.

GODOY, L.J.G. de et al. Uso do clorofilômetro no manejo da adubação nitrogenada para milho em sucessão a pastagem de Brachiaria decumbens. Ciência Rural, v.37, p.38-44, 2007. Disponível em $<$ http://www.scielo.br/scielo.php?script=sci_arttext\&pid=S010384782007000100007\&lng=pt\&nrm=iso $>$. Acesso em: 6 abr. 2011. doi: 10.1590/S0103-84782007000100007.

HAWKINS, J.A. et al. Using relative chlorophyll meter values to determine nitrogen application rates for corn. Agronomy Journal, v.99, p.1034-1040, 2007. Disponível em: <https:// www.agronomy.org/publications/aj/articles/99/4/ 1034?highlight=JmFydGljbGVfeWVhcj0yMDA3JmFydGljbGVfd m9sdW1lPTk5JmFydGljbGVfZmlyc3RwYWdlPTEwMzQmcT1 IQVdLSU5TJTJDK09SK0ouQSZsZW49MTAmc3RhcnQ9MSZzdGVt PWZhbHNlJnNvcnQ9>. Acesso em: 6 abr. 2011. doi: 10.2134/ agronj2006.0309.

PIEKIELEK, W.P. et al. Use of a chlorophyll meter at the early dent stage of corn to evaluate nitrogen sufficiency. Agronomy Journal, v.87, n.3, p.403-408, 1995. Disponível em: <https://www.agronomy.org/publications/aj/abstracts/87/3/ AJ0870030403>. Acesso em: 6 abr. 2011. doi: 10.2134/ agronj1995.00021962008700030003x.

RAIJ, B. van. Fertilidade do solo e adubação. Piracicaba: Ceres/Potafos, 1991. 343p.

RAIJ, B. et al. Recomendações de adubação e calagem para o estado de São Paulo. 2.ed. Campinas: IAC, 1996. 285p. (Boletim Técnico, 100).

RITCHIE, S.W. et al. Como a planta de milho se desenvolve. Informações agronômicas, n.103, p.1-11, 2003.

RAMBO, L. et al. Adequação de doses de nitrogênio em milho com base em indicadores de solo e de planta. Pesquisa Agropecuária Brasileira, v.43, p.401-409, 2008. Disponível em <http:// www.scielo.br/scielo.php?script=sci_arttext\&pid=S0100- 
204X2008000300016\&lng=pt\&nrm=iso>. Acesso em: 6 abr. 2011. doi: 10.1590/S0100-204X2008000300016.

SOUSA, D.M.G.; LOBATO, E. Calagem e adubação para culturas anuais e semiperenes. In: ___ _ C__ Cerrado: correção do solo e adubação. Planaltina-DF: Embrapa Cerrados, 2004. p.283-315.

VARVEL, G.E. et al. Ability for in-season correction of nitrogen deficiency in corn using chlorophyll meter. Soil Science Society of America Journal, v.61, n.4, p.1233-1239, 1997. Disponível em: <https://www.soils.org/publications/sssaj/ abstracts/61/4/SS0610041233>. Acesso em: 6 abr. 2011. doi: 10.2136/sssaj1997.03615995006100040032x.
WASKOM, R.M. et al. Monitoring nitrogen status of corn with a portable chlorophyll meter. Communications in Soil Science and Plant Analysis, v.27, n.3-4, p.545-560, 1996. Disponível em: <http://www.informaworld.com/smpp/ content $\sim \mathrm{db}=\mathrm{all} \sim$ content $=\mathrm{a} 905362454 \sim \mathrm{frm}=\mathrm{abslink}>$. Acesso em: 6 abr. 2011. doi: 10.1080/00103629609369576.

ZHANG, J. et al. Sensitivity of chlorophyll meters for diagnosing nitrogen deficiencies of corn in production agriculture. Agronomy Journal, v.100, n.3, p.543-550, 2008. Disponível em: <https://www.agronomy.org/publications/aj/ articles/100/3/543>. Acesso em: 6 abr. 2011. doi: 10.2134/ agronj2006.0153. 